\title{
Silencing FOXC1 inhibits growth and migration of human oral squamous cell carcinoma cells
}

\author{
ZHONGJUN LIU $^{1 *}$, SHUAIMEI XU ${ }^{1 *}$, HONGXING CHU ${ }^{2}$, YU LU $^{1}$, PEIYAN YUAN ${ }^{1}$ and XIONGQUN ZENG ${ }^{1}$ \\ Departments of ${ }^{1}$ Endodontics and ${ }^{2}$ Oral and Maxillofacial Surgery, Stomatological Hospital, \\ Southern Medical University, Guangzhou, Guangdong 510280, P.R. China
}

Received March 11, 2018; Accepted July 13, 2018

DOI: $10.3892 /$ etm.2018.6627

\begin{abstract}
Forkhead box C1 (FOXC1) is a transcription factor that serves an important role in regulating tumorigenesis and cancer progression. However, the expression and functional role of FOXC1 in oral squamous cell carcinoma (OSCC) remains unclear. FOXC1 protein expression was determined using immunohistochemical staining of OSCC tissues and normal tissues. Cell Counting Kit-8, colony formation, migration and 5-ethynyl-2'-deoxyuridine assays were performed to investigate the role and underlying mechanism of action of FOXC1 in OSCC. A consistent increase in the immunoreactive intensity of FOXC1 in OSCC tissues as compared with that in adjacent normal tissues was demonstrated. Knockdown of FOXC1 impaired cell growth and colony formation by inhibiting cell proliferation and reducing cyclin $\mathrm{B} 1$ and cyclin D1 levels in OSCC cells. FOXC1-silenced OSCC cells exhibited decreased migration compared with that demonstrated by the control cells, accompanied by a downregulation of matrix metalloproteinase (MMP)-2 and MMP-9. Collectively, the results of the present study demonstrated that $F O X C 1$ functions as an oncogene in OSCC and may be an important therapeutic target and predictive biomarker for OSCC.
\end{abstract}

\section{Introduction}

Oral squamous cell carcinoma (OSCC) is one of the most common head and neck malignancies, comprising $90 \%$ of all oral malignancies $(1,2)$. Multiple factors including genetic alterations, environmental risk factors and viral infections are the primary causes for OSCC development and progression. Alongside the progress in therapeutic technology,

Correspondence to: Dr Xiongqun Zeng, Department of Endodontics, Stomatological Hospital, Southern Medical University, 366 Jiangnan Avenue South, Guangzhou, Guangdong 510280, P.R. China

E-mail: xiongqun_zeng@163.com

*Contributed equally

Key words: oral squamous cell carcinoma, forkhead box C1, proliferation, migration radiotherapy, chemotherapy, traditional surgery and targeted therapy are used in the treatment of OSCC (3). Although much progress has occurred in previous years in the treatment of OSCC, the overall 5-year survival rate of patients with OSCC remains unsatisfactory, at $\sim 50 \%$ (4). Therefore, understanding the molecular mechanisms underlying OSCC development and progression is necessary for improving the survival rate of patients.

Forkhead box protein $\mathrm{C} 1$ (FOXC1) belongs to the FOX family of transcription factors and functions as an important regulator in ocular development during the embryonic stage (5). Previous studies have demonstrated the role of FOXC1 as an oncogene in a diverse range of cancer types: Hypoxic stresses significantly induced FOXC1 expression in lung cancer and FOXC1 promoted the proliferation, migration, invasion, angiogenesis and epithelial-mesenchymal transition (EMT) of lung cancer cells (6). High levels of FOXC1 expression were identified in human cervical cancer tissues and was significantly associated with advanced clinical stages, a high degree of malignancy and a poor outcome (7). Furthermore, FOXC1 knockdown suppressed cell growth and induced apoptosis (7). In nasopharyngeal carcinoma (NPC), FOXC1 expression was upregulated and positively associated with lymph node metastasis, distant metastasis and an advanced clinical stage in patients with NPC (8). Knockdown of FOXC1 in NPC cells also inhibited the migratory and invasive abilities of cells (8). Collectively, FOXC1 may be an effective therapeutic target for cancer. However, the expression and biological function of FOXC1 in OSCC remains unclear. In the present study, FOXC1 expression was detected in human OSCC tissues using immunohistochemical (IHC) staining and the potential biological role of FOXC1 in OSCC cell lines was investigated. The results suggested that silencing FOXC1 inhibits the growth and migration of OSCC, which may provide experimental evidence for the role of $\mathrm{FOXC1}$ in the diagnosis and treatment of OSCC.

\section{Materials and methods}

Clinical samples. All of the experiments in the present study were approved by the Medical Ethics Committee of the Stomatological Hospital, Southern Medical University (Guangzhou, China). Informed consent was provided by the patients, who agreed to the use of their tissues in the present 
study. A total of 42 archival cases that were diagnosed and treated from January 2014 to August 2016 at the Stomatological Hospital, Southern Medical University, of which 15 cases (age range, 51-68 years; 7 females and 8 males) were healthy controls and 27 were cases of OSCC (age range, 50-74 years; 12 females and 15 males), were included. The collected tissues were embedded by paraffin following dehydration with an ethanol series $(70,80,90,95$ and $100 \%)$ and $100 \%$ xylene treatment at room temperature, and then stored at $4^{\circ} \mathrm{C}$ until use.

IHC staining. For IHC staining, $4-\mu \mathrm{m}$ thick paraffin-embedded tissue sections were deparaffinized at room temperature with xylene, and then rehydrated in a descending ethanol series (100, 95 and $80 \%$ ethanol, then PBS) at room temperature. Then, $3 \% \mathrm{H}_{2} \mathrm{O}_{2}$ in methanol (v/v) was added to block the endogenous peroxidase activity at room temperature for 10 min. Following blocking with $5 \%$ bovine serum albumin (Beyotime Institute of Biotechnology, Haimen, China) in PBS for $30 \mathrm{~min}$ at room temperature, the slides were incubated overnight with the primary anti-FOXC1 antibody (1:100; cat. no. DF3252; Affinity Biosciences, Cincinnati, $\mathrm{OH}, \mathrm{USA})$ at $4^{\circ} \mathrm{C}$ overnight. Subsequent to incubation with the horseradish peroxidase-conjugated goat anti-rabbit horseradish peroxidase-conjugated immunoglobulin (Ig)G (1:200; cat. no. S0001; Affinity Biosciences) for $2 \mathrm{~h}$ at room temperature, the DAB substrate kit (Fuzhou Maixin Biotech Co., Ltd., Fuzhou, China) was used to detect positively stained cells. The slide was photographed by a fluorescence microscope (Olympus CX31-32RFL; Olympus Corporation, Tokyo, Japan) at a magnification of $x 40$. The number of positive and total cells in each frame were counted and analyzed. The IHC score was quantified as follows: $0,0-20 \%$ positive cells; $1,20-40 \%$; $2,40-60 \%$; 3, 60-80\%; 4, 80-100\%.

Cell lines and cell cultures. The UM-SCC-1 (SCC-1) and UM-SCC-23 (SCC-23) cell lines were obtained from Dr Li Cui (University of California Los Angeles School of Dentistry, Los Angeles, CA, USA). These cells were maintained in Dulbecco's modified Eagle's medium (DMEM; Gibco; Thermo Fisher Scientific, Inc.) containing 10\% fetal bovine serum (FBS; Gibco; Thermo Fisher Scientific, Inc.), $100 \mathrm{U} / \mathrm{ml}$ penicillin and $100 \mathrm{mg} / \mathrm{ml}$ streptomycin (Gibco-BRL; Thermo Fisher Scientific, Inc) at $37^{\circ} \mathrm{C}$ with $5 \% \mathrm{CO}_{2}$ in a humidified incubator.

Lentivirus infection. The lentivirus-based short hairpin (sh)RNA (5'-GGGAAACTGTATTAATCTTAT-3') targeting FOXC1 and negative control (shNC; 5'-GATCCGACT TCATAAGGCTTC-3'), which was a scrambled sequence with no homology to human genes were purchased from GeneCopoeia, Inc., (Rockville, MD, USA). The lentiviral particles were generated by following a standardized protocol using the QIAGEN Plasmid Mini kit (Qiagen GmbH, Hilden, Germany), and EndoFectin-Lenti ${ }^{\mathrm{TM}}$ and TiterBoost ${ }^{\mathrm{TM}}$ reagents (both GeneCopoeia, Inc., Rockville, MD, USA). The lentiviral transfer vector was co-transfected into 293Ta cells (cat. no. CLv-PK-01) with Lenti-Pac ${ }^{\text {TM }}$ HIV packaging mix (cat. no. HPK-LvTR-20). The lentivirus particles were purified using centrifugation $\left(3,500 \times \mathrm{g}, 4^{\circ} \mathrm{C}, 25 \mathrm{~min}\right)$ and stored at $-80^{\circ} \mathrm{C}$ in aliquots. The lenti-shFOXC1 and lenti-shNC were used to infect SCC-1 and SCC-23 cell lines at a multiplicity of infection (MOI) of 20. For each well, $0.5 \mathrm{ml}$ lenti-shFOXC1 or lenti-shNC suspension diluted in DMEM (Gibco; Thermo Fisher Scientific, Inc.) with Polybrene (Santa Cruz Biotechnology, Inc., Dallas, TX, USA) at a final concentration of $5-8 \mu \mathrm{g} / \mathrm{ml}$. After a $72-\mathrm{h}$ infection at $37^{\circ} \mathrm{C}$ in a $5 \%$ $\mathrm{CO}_{2}$ atmosphere, puromycin $(2 \mu \mathrm{g} / \mathrm{ml}$; Beyotime Institute of Biotechnology, Haimen, China) was added to select the stably infected cells at $37^{\circ} \mathrm{C}$ with $5 \% \mathrm{CO}_{2}$ in a humidified incubator.

Purification of total RNA and reverse transcription quantitative polymerase chain reaction ( $R T-q P C R)$. Quick-RNA MiniPrepKit (Zymo Research Corp., Irvine, CA, USA) was used to extract the total RNA from OSCC cells, according to the manufacturer's protocol. cDNA was synthesized using the Prime-Script RT reagent kit (cat. no. RR140A) and the qPCR using the SYBR Premix DimerEraser kit (cat. no. RR840A) (both from ; Takara Bio, Inc., Otsu, Japan), following the protocol of manufacturer. RT was performed using $1 \mu \mathrm{g}$ total RNA in $2 \mu \mathrm{l}$ water at $65^{\circ} \mathrm{C}$ for $5 \mathrm{~min}, 30^{\circ} \mathrm{C}$ for $10 \mathrm{~min}, 42^{\circ} \mathrm{C}$ for $10-30 \mathrm{~min}$ and $2^{\circ} \mathrm{C}$ for $3 \mathrm{~min}$. The qPCR conditions were as follows: Denaturation at $94^{\circ} \mathrm{C}$ for $2 \mathrm{~min}$, then denaturation for 30 cycles at $94^{\circ} \mathrm{C}$ for $30 \mathrm{sec}$, annealing at $58^{\circ} \mathrm{C}$ for $30 \mathrm{sec}$ and extension at $72^{\circ} \mathrm{C}$ for $30 \mathrm{sec}$, followed by a terminal elongation step at $72^{\circ} \mathrm{C}$ for $10 \mathrm{~min}$. The following qPCR primers were used: FOXC1: Forward, 5'-CATTTTGGT CTAGGGTGGTTTC-3'; reverse, 5'-TCTGATTGGCAGGGC AGAT-3' and GAPDH: Forward, 5'-CCAGGTGGTCTCCTC TGACTTC-3'; reverse, 5'-GTGGTCGTTGAGGGCAAT-3'. (Sangon Biotech Co., Ltd., Shanghai, China). Relative mRNA expression was calculated using $2^{-\Delta \Delta C q}(9)$. The qPCR reaction was performed using the ABI ViiA 7 real-time PCR system (Thermo Fisher Scientific, Inc.). GAPDH was used as an internal control.

Western blot analysis. Western blot analysis was performed as described previously (10). Total protein was extracted from SSC1 and SCC23 cells infected with lenti-shNC or lenti-shFOXC1 with RIPA lysis buffer (Beyotime Institute of Biotechnology). The concentration of total protein was measured with a BCA kit (Beyotime Institute of Biotechnology). Protein (10 $\mu \mathrm{g} /$ lane) was separated using $10 \%$ SDS-PAGE gel and transferred onto polyvinylidene difluoride membranes (EMD Millipore, Billerica, MA, USA) at $200 \mathrm{~mA}$ for $2 \mathrm{~h}$. The blots were then blocked with $5 \%$ skimmed milk in TBS/T buffer for $1 \mathrm{~h}$ at room temperature, incubated overnight at $4^{\circ} \mathrm{C}$ with the primary anti-FOXC1 (cat. no. 8758; 1:500), anti-matrix metalloproteinase (MMP)-2 (cat. no. 40994; 1:800), anti-MMP-9 (cat. no. 13667; 1:500), anti-cyclin B1 (cat. no. 12231; 1:1,000), anti-cyclin D1 (cat. no. 2922; 1:1,000) and anti-GAPDH (cat. no. 51332, 1:5,000; all Cell Signaling Technology, Inc., Danvers, MA, USA) antibodies, and incubated with horseradish peroxidase-conjugated goat anti-rabbit $\operatorname{IgG}(1: 3,000)$ for $2 \mathrm{~h}$ at room temperature. Immunoreactive proteins were visualized using ECL Plus reagent (Beyotime Institute of Biotechnology). ImageJ software (version 1.8.0; National Institutes of Health, Bethesda, MD, USA) was used for densitometric analysis. Each assay was repeated 3 times. 
A

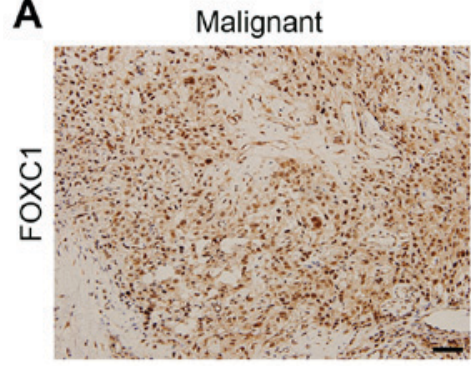

Normal

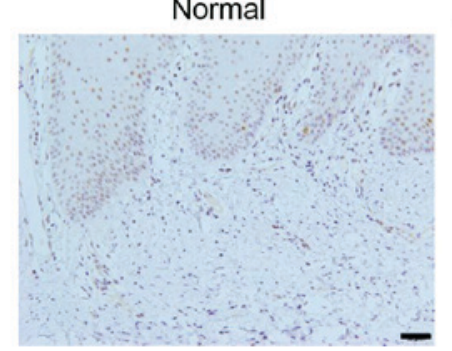

B

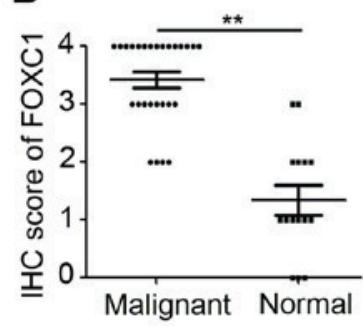

Figure 1. Upregulation of FOXC1 expression in OSCC tissues. (A) IHC staining of FOXC1 expression in OSCC tissues and adjacent normal tissues. Scale bar, $100 \mu \mathrm{m}$. (B) The FOXC1 expression in OSCC tissues and adjacent normal tissues was analyzed according to the IHC score of each sample. (n=27 for OSCC tissues; $\mathrm{n}=15$ for adjacent normal tissues; $\left.{ }^{* *} \mathrm{P}<0.01\right)$. FOXC1, forkhead box $\mathrm{C} 1$; OSCC, oral squamous cell carcinoma; IHC, immunohistochemical.

5-Ethynyl-2'-deoxyuridine (EdU) assay. The EdU detection kit (Guangzhou Ribobio Co., Ltd., Guangzhou, China) was used to evaluate cell proliferation. According to the manufacturer's protocol, cells were treated with $25 \mathrm{mmol} / 1 \mathrm{EdU}$ for $6 \mathrm{~h}$ at $37^{\circ} \mathrm{C}$ and fixed with $4 \%$ paraformaldehyde at room temperature for $30 \mathrm{~min}$. Following incubation with $2 \mathrm{mg} / \mathrm{ml}$ glycine for $5 \mathrm{~min}$, cells were treated with $0.5 \%$ Triton X-100 (Sigma-Aldrich; Merck KGaA, Darmstadt, Germany) for $20 \mathrm{~min}$ and stained with 1X Apollo reaction cocktail (Guangzhou Ribobio Co., Ltd.) for $30 \mathrm{~min}$ at room temperature. Following washing with $0.5 \%$ Triton X-100 in PBS, 1 X Hoechst dye (Beyotime, Beijing, China) was used to incubate cells at room temperature for $30 \mathrm{~min}$. Images were captured using a confocal laser scanning microscope (magnification, x100). Following the merging of the images, the ratios of Apollo staining-positive cells to Hoechst staining-positive ones were calculated using ImageJ software (version 1.8.0; National Institutes of Health, Sacaton, AZ, USA). The assay was repeated in triplicate.

Cell counting kit-8 (CCK-8) assay. SCC-1 and SCC-23 cells that were stably infected with lenti-shFOXC1 or lenti-shNC were starved for $24 \mathrm{~h}$ and then seeded into a 96-well plate at a density of 4,000 cells/well in $100 \mu \mathrm{l}$ culture medium. Following cell plating for $0,24,48$ and $72 \mathrm{~h}, 10 \mu \mathrm{l}$ CCK-8 (Sigma-Aldrich; Merck KGaA) was added to each well. Following incubation for $2 \mathrm{~h}$ at $37^{\circ} \mathrm{C}$, the absorbance (OD $450 \mathrm{~nm}$ ) was measured using a microculture plate reader (Tecan Group, Ltd., Männedorf, Switzerland). All experiments were repeated three times.

Colony formation assay. SCC-1 and SCC-23 (2,000) cells that were stably infected with lenti-shFOXC1 or lenti-shNC were plated in 6-well plated with $2 \mathrm{ml}$ DMEM containing $10 \%$ FBS. Following cell culturing for 14 days at $37^{\circ} \mathrm{C}$ in a $5 \% \mathrm{CO}_{2}$ atmosphere, the cells were fixed in $100 \%$ methanol at room temperature for $10 \mathrm{~min}$ and stained with $0.1 \%$ crystal violet for $10 \mathrm{~min}$ at room temperature. The colonies in each well were counted using an inverted microscope (Olympus IX51; Olympus Corporation; magnification, $\mathrm{x} 40$ ) and relative colony numbers were calculated as follows: The colony numbers of shFOXC1/the colony numbers of shNC.

Migration assay. SCC-1 and SCC-23 cells that were stably infected with lenti-shFOXC1 or lenti-shNC were starved for 24 h. Cells were then harvested with Trypsin (Gibco; Thermo
Fisher Scientific, Inc.), centrifuged at $200 \mathrm{x}$ g for $5 \mathrm{~min}$ at room temperature, resuspended in DMEM containing $0.1 \%$ FBS and added to the upper chamber of Transwell chambers $(8 \mu \mathrm{m}$ pore size; Corning Incorporated, Corning, NY, USA), while DMEM containing $10 \%$ FBS was added to the lower chambers. Following culturing at $37^{\circ} \mathrm{C}$ in a $5 \% \mathrm{CO}_{2}$ atmosphere for $48 \mathrm{~h}$, the cells were fixed at room temperature for $10 \mathrm{~min}$ in $100 \%$ methanol and stained for $10 \mathrm{~min}$ at room temperature with $0.1 \%$ crystal violet. Cells that had moved through the membrane were counted from 3 random fields using an inverted microscope (Olympus IX51; magnification, x40).

Statistical analysis. Data are expressed as mean \pm standard deviation. The paired sample t-test was used to compare the results between two groups and a one-way analysis of variance followed by Tukey's post-hoc test was performed to analyze the difference between $\geq$ three groups using SPSS v21.0 software (SPSS Inc., Chicago, IL, USA). P $<0.05$ was considered to indicate a statistically significant difference.

\section{Results}

Expression of FOXC1 in OSCC and adjacent normal tissues. To evaluate the expression of FOXC1 in human tissue samples, 27 OSCC tissue samples and 15 normal tissue samples healthy controls were collected for IHC staining. As indicated in Fig. 1A, positive staining of epithelial cells was identified as the presence of yellow-brown granules. Positive staining was observed in the cell nuclei of OSCC tissues throughout the epithelium and the tumor (Fig. 1A). Whereas positive staining in normal tissues was almost absent and detected only in the most active parabasal and basal layers (Fig. 1A). Additional analysis suggested that the density of FOXC1 staining in OSCC tissues was increased compared with that in adjacent normal tissues (Fig. 1B). These results demonstrated the upregulation of FOXC1 in OSCC.

Knockdown of FOXCl inhibits OSCC growth in vitro. To investigate the potential biological effects of FOXC1 in OSCC, shRNA targeting the FOXC1 gene was used to inhibit FOXC1 expression in the OSCC cell lines, SCC-1 and SCC-23. As indicated in Fig. 2A, FOXC1 mRNA expression was efficiently downregulated by lenti-shFOXC1 in SCC-1 and SCC-23 cells. Western blot analysis also confirmed the inhibition of FOXC1 protein production by shFOXC1 in the SCC-1 and SCC-23 cell lines (Fig. 2B). The CCK-8 assay was performed to determine 


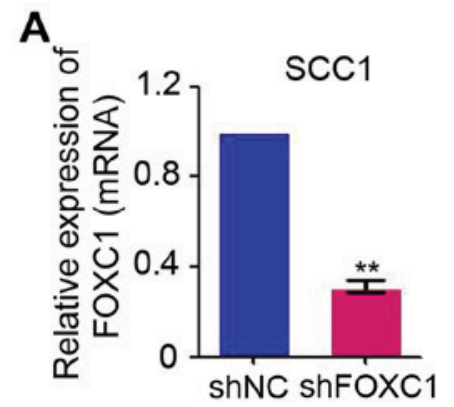

C

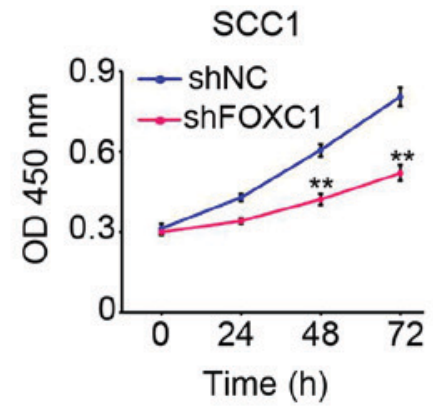

D

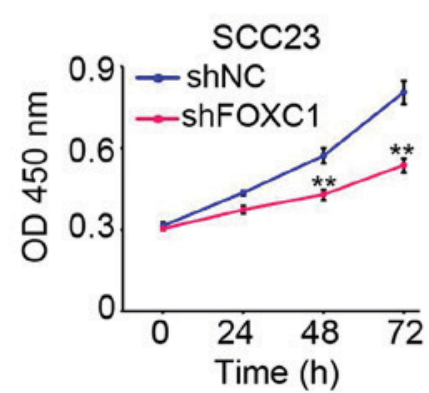

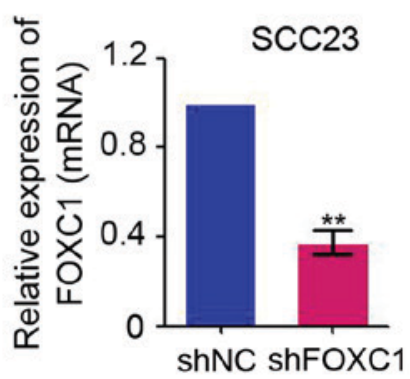

E

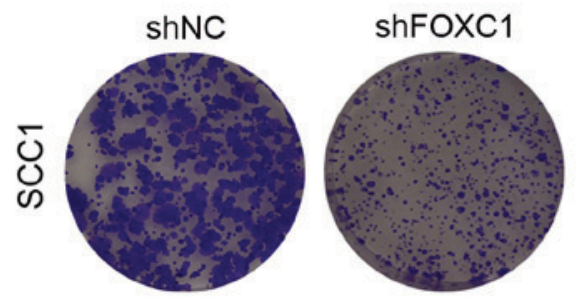

F

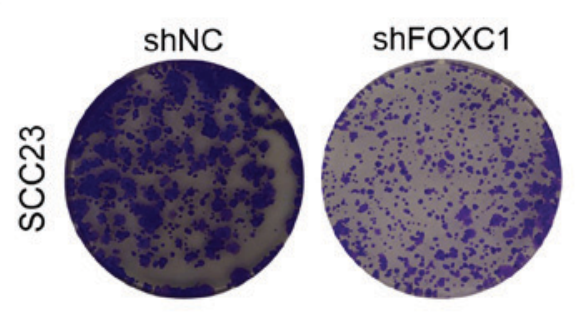

B

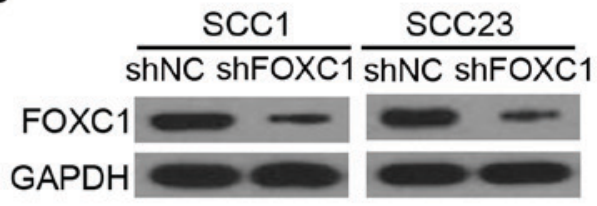

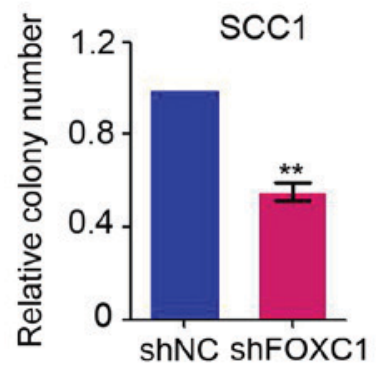

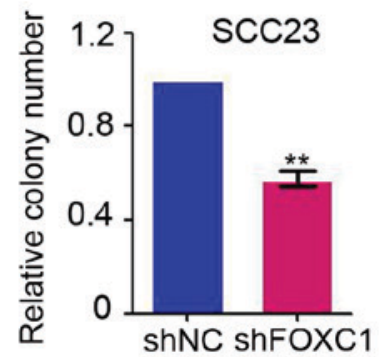

Figure 2. Knockdown of FOXC1 inhibits OSCC cell growth in vitro. (A) Quantitative polymerase chain reaction analysis of FOXC1 mRNA expression in SCC-1 and SCC-23 cells infected with lenti-shFOXC1 or lenti-shNC. ( $\mathrm{n}=3$ for each group; ${ }^{* *} \mathrm{P}<0.01$ vs. shNC group). (B) Western blot analysis of FOXC1 expression in SCC-1 and SCC-23 cells infected with lenti-shFOXC1 or lenti-shNC. Cell-counting Kit-8 was used to investigate the viability of (C) SCC-1 and (D) SCC-23 cells infected with lenti-shFOXC1 or lenti-shNC for $0,24,48$, and $72 \mathrm{~h}$. ( $\mathrm{n}=5$ for each group; ${ }^{* *} \mathrm{P}<0.01 \mathrm{vs.} \mathrm{shNC}$ group). Colony formation assays were performed in (E) SCC-1 and (F) SCC-23 cells infected with lenti-shFOXC1 or lenti-shNC. The number of colonies formed was counted and the relative colony formation was analyzed. ( $\mathrm{n}=3$ for each group; ${ }^{* *} \mathrm{P}<0.01$ vs. shNC group). FOXC1, forkhead box $\mathrm{C} 1$; OSCC, oral squamous cell carcinoma; si, small interfering; NC, negative control; OD, optical density.

the role of FOXC1 in the growth of OSCC and the results indicated that there was significant inhibition of cell growth in FOXC1-knockdown SCC-1 and SCC-23 cells at 48 and $72 \mathrm{~h}$ post-infection (Fig. 2C and D). Additional colony formation assay results also confirmed the inhibition of cell growth in FOXC1-knockdown SCC-1 and SCC-23 cells (Fig. 2E and $\mathrm{F})$. Collectively, these data confirmed the oncogenic role of FOXC1 in OSCC.

Downregulation of FOXC1 inhibits the proliferative capacity of OSCC cells. To investigate the role of FOXC1 in the proliferation of OSCC, EdU assays were performed in the OSCC SCC-1 and SCC-23 cell lines, which were infected with lentiviruses expressing shRNA targeting FOXC1 or the NC. As demonstrated in Fig. 3A and B, proliferative cells were observed in shFOXC1 and shNC-infected cells. However, there were fewer proliferative SCC-1 and SCC-23 cells following FOXC1 knockdown compared with the paired shNC cells
(Fig. 3A and B). Furthermore, western blot analysis indicated a marked downregulation of cyclin B1 and cyclin D1 levels in SCC-1 and SCC-23 cells following lenti-shFOXC1 infection, as compared with that in lenti-shNC-infected cells (Fig. 3C). These results suggested that the downregulation of FOXC1 suppressed the proliferative capacity of OSCC cells through the regulation of cyclin levels.

Downregulation of FOXC1 inhibits the migration capacity of OSCC cells. To determine the potential regulatory role of FOXC1 in the migration of OSCC cells, Transwell chamber-based cell migration assays were performed. Microscopic images of the Transwell chamber assays are presented in Fig. 4A and B. The migration of SCC-1 and SCC-23 cells in shFOXC1-infected groups were suppressed by $52.7 \pm 4.3$ and $61.2 \pm 3.7 \%$, respectively, as compared with that in the corresponding shNC groups (Fig. 4A and B). Accordingly, the expression of MMP-2 and MMP-9 in SCC-1 and SCC-23 
A
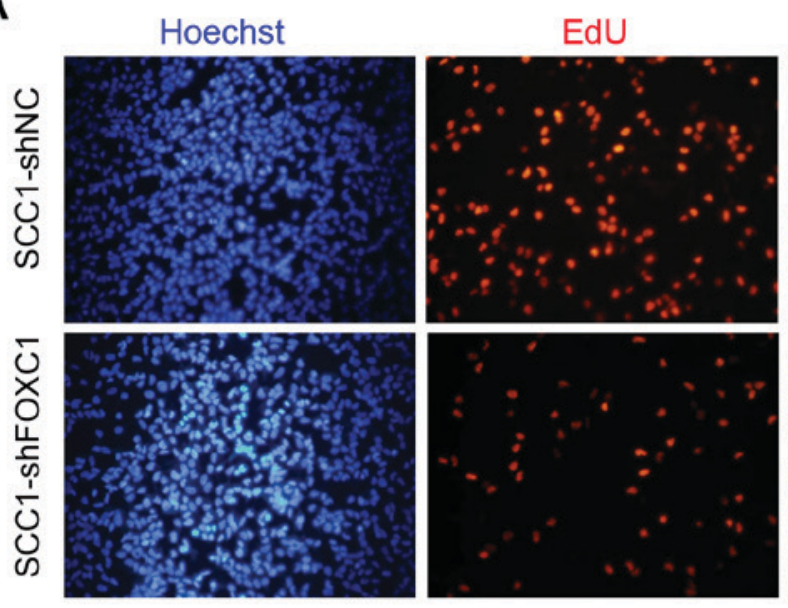

B
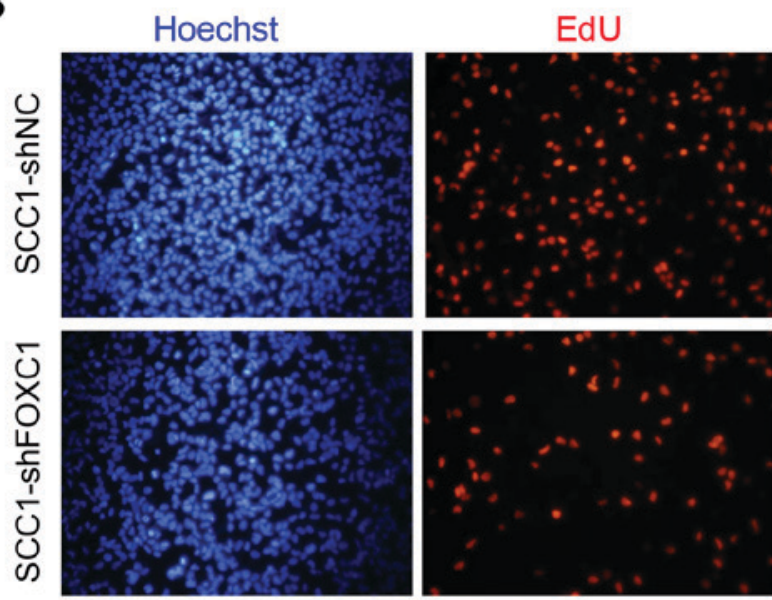

C

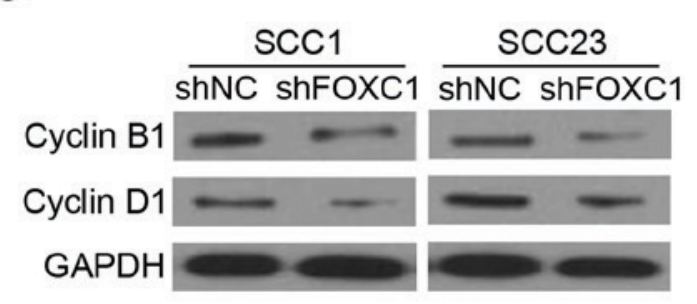

Hoechst+EdU

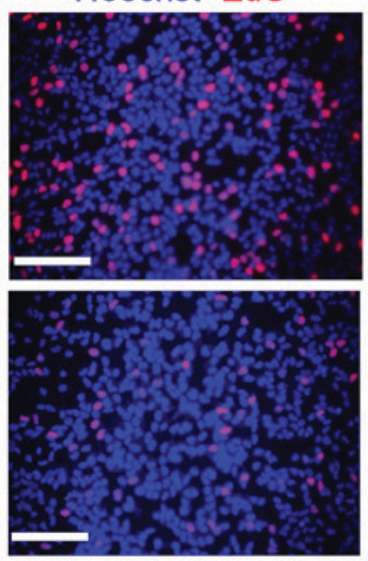

Hoechst+EdU
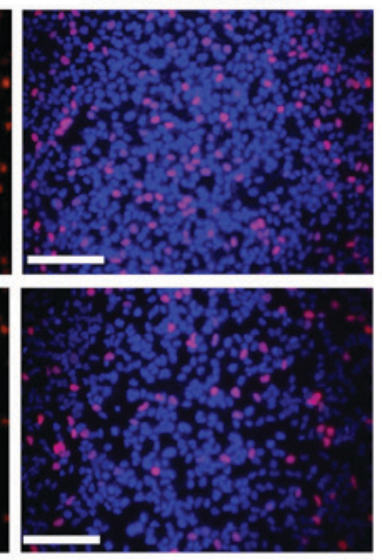
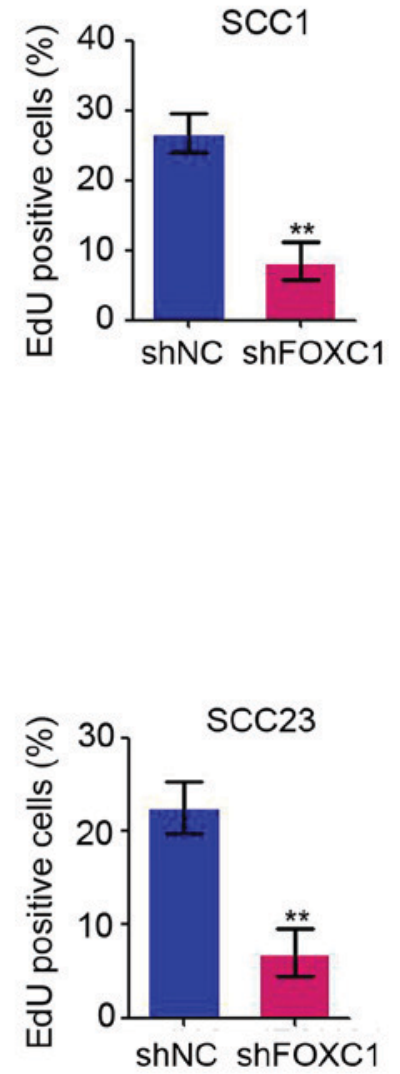

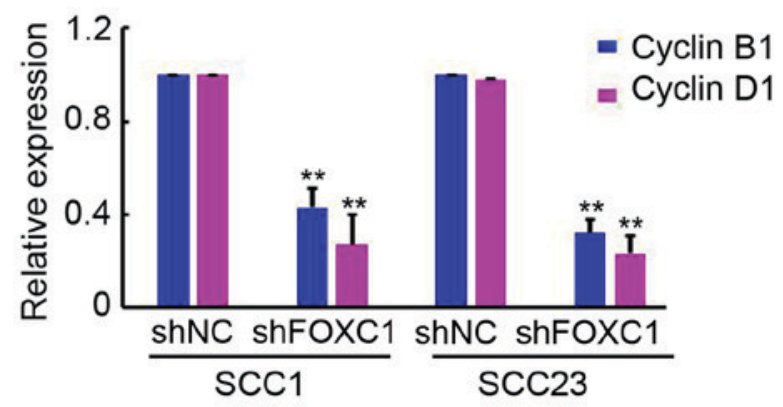

Figure 3. Knockdown of FOXC1 inhibits OSCC cell proliferation. (A and B) EdU assay was performed to detect the status of proliferation in SCC-1 and SCC-23 cells that were infected with lenti-shFOXC1 or lenti-shNC for $48 \mathrm{~h}$. Red coloring indicates proliferating cells and the cell nuclei were stained with Hoechst (blue). The percentage of EdU-positive cells in each field of view was analyzed. (Scale bar, $100 \mu \mathrm{m}$. $\mathrm{n}=4 \mathrm{for}$ each group; ${ }^{* *} \mathrm{P}<0.01 \mathrm{vs}$. shNC group). (C) Western blot analysis of cyclin B1 and cyclin D1 expression in SCC-1 and SCC-23 cells that were infected with lenti-shFOXC1 or lenti-shNC for 48 h. GAPDH was used as a loading control. The relative expression of cyclin B1 and cyclin D1 was analyzed ( $\mathrm{n}=3$ for each group; ${ }^{* *} \mathrm{P}<0.01 \mathrm{vs}$. shNC group). FOXC1, forkhead box C1; OSCC, oral squamous cell carcinoma; si, small interfering; NC, negative control; EdU, 5-ethynyl-2'-deoxyuridine.

cells was significantly decreased following the silencing of FOXCl (Fig. 4C). These results demonstrated a stimulatory role of FOXCl in the migration of OSCC cells.

\section{Discussion}

FOXC1 is a $3,500 \mathrm{bp}$ transcription factor, which is located on chromosome $6 \mathrm{p} 25$ (11). FOXC1 protein consists of active domain 1, a forkhead domain and active domain 2 (11). The present study demonstrated the upregulation of FOXC1 in OSCC tissues. Additional experimental results suggested that silencing FOXCl inhibited OSCC cell growth and migration through the regulation of cyclin and MMP protein levels.

Previous studies have demonstrated the deregulation of FOXC1 in a diverse range of cancer types (12-16). Increased 
A $\operatorname{shNC}$ ShFOXC1
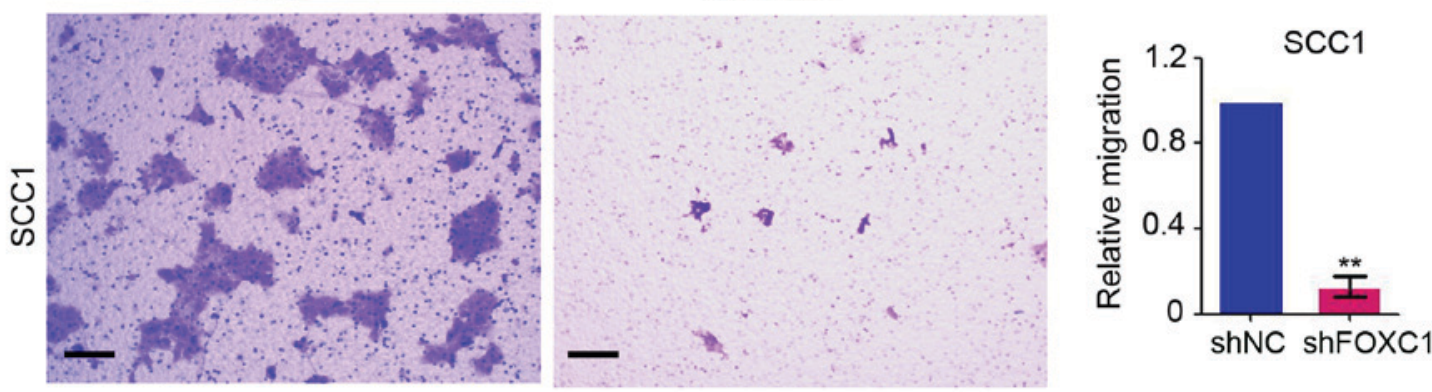

B
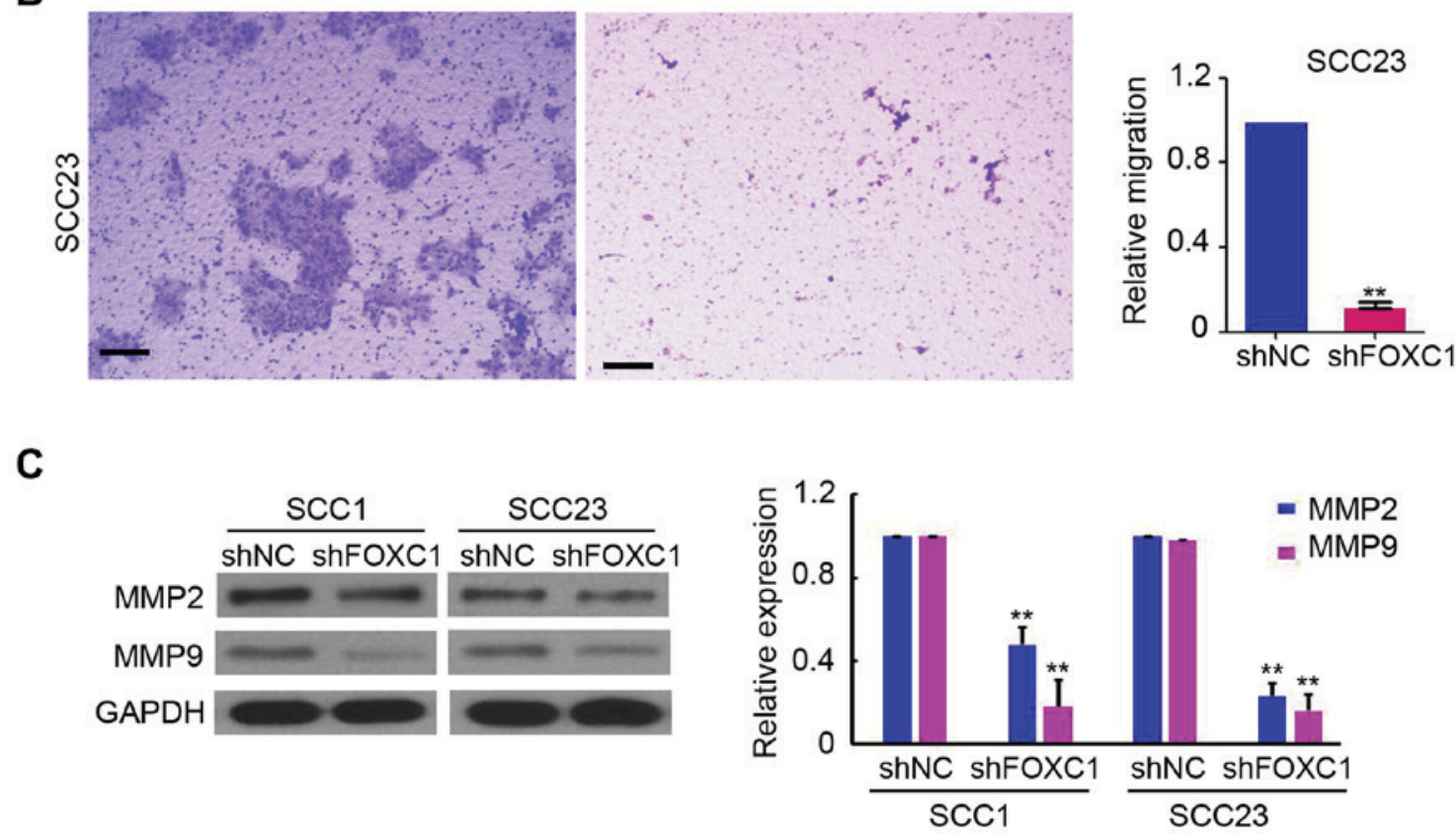

Figure 4. Knockdown of FOXC1 inhibits OSCC cell migration. The Transwell chambers-based migration assay was used to investigate the migration ability of (A) SCC-1 and (B) SCC-23 cells that were infected with lenti-shFOXC1 or lenti-shNC for $48 \mathrm{~h}$. Images of the migrated cells were captured and counted. The relative migration ability was analyzed. (Scale bar, $50 \mu \mathrm{m}$. $\mathrm{n}=4$ for each group; ** $\mathrm{P}<0.01 \mathrm{vs}$. shNC group). (C) Western blot analysis of MMP-2 and MMP-9 expression in SCC-1 and SCC-23 cells infected with lenti-shFOXC1 or lenti-shNC for $48 \mathrm{~h}$. GAPDH was used as a loading control. The relative expression of MMP-2 and MMP-9 was analyzed ( $\mathrm{n}=3$ for each group; ${ }^{* *} \mathrm{P}<0.01$ vs. shNC group). $\mathrm{FOXC1}$, forkhead box $\mathrm{Cl}$; OSCC, oral squamous cell carcinoma; si, small interfering; NC, negative control; MMP, matrix metalloproteinase.

expression of FOXC1 was identified in hepatocellular carcinoma cell (HCC) lines, partly contributing to the induction of interleukin 8 (IL-8) (14). Furthermore, patients with HCC who exhibited positive FOXC1 expression demonstrated decreased survival and higher recurrence rates compared with those who exhibited negative FOXC1 expression (12). FOXC1 mRNA and protein levels were overexpressed in pancreatic ductal adenocarcinoma tissue as compared with corresponding normal tissue, and the overexpression of FOXC1 was significantly associated with the clinical stage, histological differentiation and presence of lymph node metastases (15). FOXC1 mRNA was also upregulated in gastric cancer and high FOXC1 expression was associated with shorter overall survival of patients compared with that in patients exhibiting low expression (16). In the present study, it was firstly demonstrated that the immunoreactive intensity of FOXC1 was consistently increased in OSCC tissues as compared with that in adjacent normal tissues. This suggested that FOXC1 may be associated with the onset and progression of this type of cancer. However, additional investigation is required to determine the predictive role of FOXC1 in the survival of patients with OSCC.

FOXC1 has been demonstrated to be correlated with Axenfeld-Rieger syndrome and embryonic development $(17,18)$. Various studies have suggested that FOCX1 serves a stimulatory role in cancer development and progression: A previous study by Hayashi and Kume (19) indicated that there was a marked interaction between FOXC1 and Notch signals, accompanied with vascular endothelial growth receptor regulating the expression of vascular genes and inducing tumor angiogenesis. Furthermore, Ray et al (20) demonstrated that patients with high FOXC1 mRNA expression exhibited a lower survival rate. In addition, ectopic FOXC1 expression increased tumor invasion by EMT, during which tumor cells undergo distal migration and invasion $(21,22)$. The results of the present study first identified that the suppression of FOXC1 markedly inhibited cell growth and migration of OSCC cells in vitro, which indicated that $\mathrm{FOXC1}$ functions as an oncogene 
in OSCC. Additional mechanistic investigations indicated that cyclin and MMP family proteins were involved in the proliferation and migration regulated by FOXC1 in OSCC.

Although the function of $\mathrm{FOXC1}$ in regulating normal biological processes and tumor progression is well known (23), the underlying mechanisms involved in the regulation of tumorigenesis and development remain unclear. Several microRNAs (miR), including miR-639 and miR-548I, are involved in modulating FOXC1 expression via post-transcriptional gene regulation during tumor progression $(24,25)$. Furthermore, in basal-like breast cancer, FOXC1 transcription was activated by epidermal growth factor receptor through the extracellular signal-regulated kinase and protein kinase B pathways (26). In addition, FOXC1 expression may be also induced by inflammation, as demonstrated by the induction of FOXC1 expression by IL- 8 through activation of phosphoinositide 3-kinase signaling (14). In early osteogenic differentiation, bone morphogenic protein 4 was identified to regulate FOXC1 expression (27). In the present study, it was demonstrated that knockdown of FOXC1 suppressed cyclin B1, cyclin D1, MMP-2 and MMP-9 expression in OSCC. However, additional studies are required to understand the mechanism underlying FOXC1-mediated regulation of OSCC formation and prognosis.

In conclusion, $\mathrm{FOXC1}$ functions as an oncogene in OSCC cells, increasing their proliferation and migration abilities. The results of the present study suggest that FOXC1 is a potential therapeutic target for the treatment of OSCC.

\section{Acknowledgements}

The authors would like to thank the kind support from Dr. Cui (University of California Los Angeles School of Dentistry and Jonsson Comprehensive Cancer Center).

\section{Funding}

The present study was supported by grants from the Natural Science Foundation of Guangdong Province (grant no., 2015A030313810), Scientific research start-up project of Southern Medical University in 2017 (grant no., PY2017N038) and Start-up project research of Southern Medical University Dental Hospital (grant no., PY2017009).

\section{Availability of data and materials}

All data generated and/or analyzed during this study are included in this published article.

\section{Authors' contributions}

ZL and SX were involved in the acquisition of the data. HC, YL and PY were involved in the analysis and interpretation of the data. XZ was involved in the conception and design of the present study and obtaining the funding.

\section{Ethics approval and consent to participate}

All of the experiments in the present study were approved by the Medical Ethics Committee of the Stomatological Hospital, Southern Medical University (Guangzhou, China). Informed consent was provided by the patients who agreed to the use of their tissues in the present study.

\section{Patient consent for publication}

Patient provided consent for their data to be published.

\section{Competing interests}

All authors declare that there are no competing interests.

\section{References}

1. Ferlay J, Shin HR, Bray F, Forman D, Mathers C and Parkin DM: Estimates of worldwide burden of cancer in 2008: GLOBOCAN 2008. Int J Cancer 127: 2893-2917, 2010.

2. Choi S and Myers JN: Molecular pathogenesis of oral squamous cell carcinoma: Implications for therapy. J Dent Res 87: 14-32, 2008.

3. Abram MH, van Heerden WF, Rheeder P, Girdler-Brown BV and van Zyl AW: Epidemiology of oral squamous cell carcinoma. SADJ 67: 550-553, 2012.

4. Fuller CD, Wang SJ, Thomas CR Jr, Hoffman HT, Weber RS and Rosenthal DI: Conditional survival in head and neck squamous cell carcinoma: Results from the SEER dataset 1973-1998. Cancer 109: 1331-1343, 2007.

5. Aldinger KA, Lehmann OJ, Hudgins L, Chizhikov VV, Bassuk AG, Ades LC, Krantz ID, Dobyns WB and Millen KJ: FOXC1 is required for normal cerebellar development and is a major contributor to chromosome 6p25.3 Dandy-Walker malformation. Nat Genet 41: 1037-1042, 2009.

6. Lin YJ, Shyu WC, Chang CW, Wang CC, Wu CP, Lee HT, Chen LJ and $\mathrm{Hsieh} \mathrm{CH}$ : Tumor hypoxia regulates forkhead box $\mathrm{C} 1$ to promote lung cancer progression. Theranostics 7: 1177-1191, 2017.

7. Wang L, Chai L, Ji Q, Cheng R, Wang J and Han S: Forkhead box protein $\mathrm{C} 1$ promotes cell proliferation and invasion in human cervical cancer. Mol Med R 17: 4392-4398, 2018.

8. Ou-Yang L, Xiao SJ, Liu P, Yi SJ, Zhang XL, Ou-Yang S, Tan SK and Lei X: Forkhead box C1 induces epithelial-mesenchymal transition and is a potential therapeutic target in nasopharyngeal carcinoma. Mol Med Rep 12: 8003-8009, 2015.

9. Livak KJ and Schmittgen TD: Analysis of relative gene expression data using real-time quantitative PCR and the 2(-Delta Delta C(T)) method. Methods 25: 402-408, 2001.

10. Dai L, Cui X, Zhang X, Cheng L, Liu Y, Yang Y, Fan P, Wang Q, Lin Y, Zhang J, et al: SARI inhibits angiogenesis and tumour growth of human colon cancer through directly targeting ceruloplasmin. Nat Commun 7: 11996, 2016.

11. Berry FB, Saleem RA and Walter MA: FOXC1 transcriptional regulation is mediated by $\mathrm{N}$ - and $\mathrm{C}$-terminal activation domains and contains a phosphorylated transcriptional inhibitory domain. J Biol Chem 277: 10292-10297, 2002.

12. Xia L, Huang W, Tian D, Zhu H, Qi X, Chen Z, Zhang Y, Hu H, Fan D, Nie Y and Wu K: Overexpression of forkhead box C1 promotes tumor metastasis and indicates poor prognosis in hepatocellular carcinoma. Hepatology 57: 610-624, 2013.

13. Xu ZY, Ding SM, Zhou L, Xie HY, Chen KJ, Zhang W, Xing CY, Guo HJ and Zheng SS: FOXC1 contributes to microvascular invasion in primary hepatocellular carcinoma via regulating epithelial-mesenchymal transition. Int J Biol Sci 8: 1130-1141, 2012.

14. Huang W, Chen Z, Zhang L, Tian D, Wang D, Fan D, Wu K and Xia L: Interleukin-8 induces expression of FOXC1 to promote transactivation of CXCR1 and CCL2 in hepatocellular carcinoma cell lines and formation of metastases in mice. Gastroenterology 149: 1053-1067.e1014, 2015.

15. Wang L, Gu F, Liu CY, Wang RJ, Li J and Xu JY: High level of FOXC1 expression is associated with poor prognosis in pancreatic ductal adenocarcinoma. Tumour Biol 34: 853-858, 2013.

16. Xu Y, Shao QS, Yao HB, Jin Y, Ma YY and Jia LH: Overexpression of FOXC1 correlates with poor prognosis in gastric cancer patients. Histopathology 64: 963-970, 2014.

17. Nishimura DY, Searby CC, Alward WL, Walton D, Craig JE, Mackey DA, Kawase K, Kanis AB, Patil SR, Stone EM and Sheffield VC: A spectrum of FOXC1 mutations suggests gene dosage as a mechanism for developmental defects of the anterior chamber of the eye. Am J Hum Genet 68: 364-372, 2001. 
18. Tanwar M, Kumar M, Dada T, Sihota R and Dada R: MYOC and FOXC1 gene analysis in primary congenital glaucoma. Mol Vis 16: 1996-2006, 2010.

19. Hayashi $\mathrm{H}$ and Kume T: Forkhead transcription factors regulate expression of the chemokine receptor CXCR4 in endothelial cells and CXCL12-induced cell migration. Biochem Biophys Res Commun 367: 584-589, 2008.

20. Ray PS, Wang J, Qu Y, Sim MS, Shamonki J, Bagaria SP, Ye X, Liu B, Elashoff D, Hoon DS, et al: FOXC1 is a potential prognostic biomarker with functional significance in basal-like breast cancer. Cancer Res 70: 3870-3876, 2010.

21. Zhou M, Ye Z, Gu Y, Tian B, Wu B and Li J: Genomic analysis of drug resistant pancreatic cancer cell line by combining long non-coding RNA and mRNA expression profling. Int J Clin Exp Pathol 8: 38-52, 2015.

22. Strizzi L, Bianco C, Normanno N, Seno M, Wechselberger C, Wallace-Jones B, Khan NI, Hirota M, Sun Y, Sanicola M and Salomon DS: Epithelial mesenchymal transition is a characteristic of hyperplasias and tumors in mammary gland from MMTV-Cripto-1 transgenic mice. J Cell Physiol 201: 266-276, 2004.

23. Lambers E, Arnone B, Fatima A, Qin G, Wasserstrom JA and Kume T: Foxc1 regulates early cardiomyogenesis and functional properties of embryonic stem cell derived cardiomyocytes. Stem Cells 34: 1487-1500, 2016.
24. Lin Z, Sun L, Chen W, Liu B, Wang Y, Fan S, Li Y and Li J: miR-639 regulates transforming growth factor beta-induced epithelial-mesenchymal transition in human tongue cancer cells by targeting FOXC1. Cancer Sci 105: 1288-1298, 2014.

25. Medina-Trillo C, Aroca-Aguilar JD, Ferre-Fernandez JJ, Méndez-Hernández CD, Morales L, García-Feijoo J and Escribano J: The role of hsa-miR-5481 dysregulation as a putative modifier factor for glaucoma-associated FOXC1 mutations. Microrna 4: 50-56, 2015.

26. Jin Y, Han B, Chen J, Wiedemeyer R, Orsulic S, Bose S, Zhang X, Karlan BY, Giuliano AE, Cui Y and Cui X: FOXC1 is a critical mediator of EGFR function in human basal-like breast cancer. Ann Surg Oncol 21 (Suppl 4): S758-S766, 2014.

27. Hopkins A, Mirzayans F and Berry F: Foxc1 expression in early osteogenic differentiation is regulated by BMP4-SMAD activity. J Cell Biochem 117: 1707-1717, 2016.

(i) $(9)$

This work is licensed under a Creative Commons Attribution-NonCommercial-NoDerivatives 4.0 International (CC BY-NC-ND 4.0) License. 